\title{
Correction to: Comparison of treatment outcomes in neck pain patients depending on the sex of the chiropractor: a prospective outcome study
}

Janine Thöni, Cynthia K. Peterson ${ }^{*}$ and B. Kim Humphreys

\section{Correction}

After publication of the original article [1] the authors noted that the presentation of the name B. Kim Humphreys was incorrect.

The authors name should be presented in the original article as:

First name: B. Kim.

Surname: Humphreys.

This has been corrected in the authorship list and reference of this Correction.

Received: 31 October 2017 Accepted: 31 October 2017

Published online: 13 November 2017

\section{Reference}

1. Thöni J, Peterson CK, Humphreys BK. Comparison of treatment outcomes in neck pain patients depending on the sex of the chiropractor: a prospective outcome study. Chiropr Man Ther. 2017;25: 18. Doi: 10.1186/s12998-017-0149-8.

* Correspondence: Cynthia.peterson@balgrist.ch 